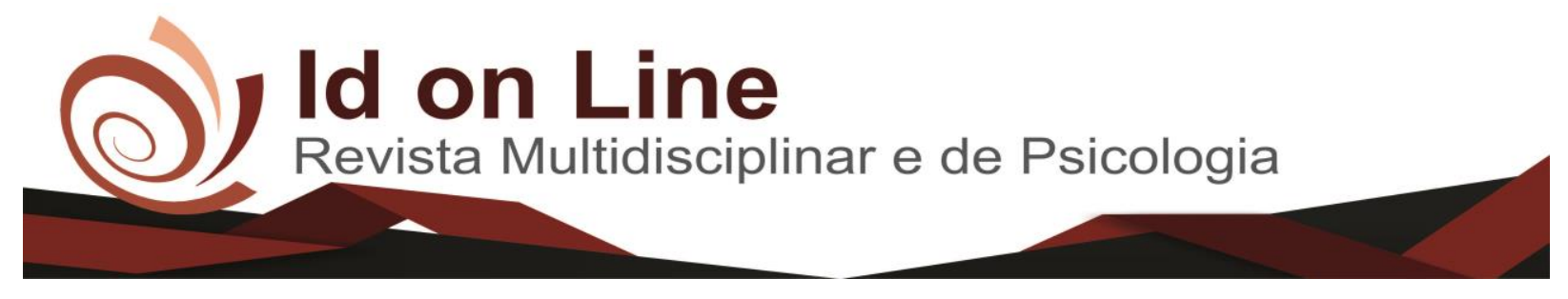

Artigo

\title{
O Monitoramento da Prática Educativa: Instrumento para uma Gestão Pedagógica Eficiente
}

Maria Benildes Uchoa de Araújo ${ }^{1}$

Resumo: Este artigo tem como objetivo refletir sobre a prática de monitoramento no desenvolvimento do processo de ensino e de aprendizagem, à partir de pesquisa de campo e bibliográfica. Teve como objeto principal, o estudo dos resultados obtidos em turmas de $2^{\circ}$ ano do Ensino Fundamental no município de Iguatu, na perspectiva de se identificar quais contribuições da ação pedagógica das escolas pesquisadas. Os resultados levaram a crer que estas foram diretamente favoráveis no sucesso dos resultados escolares.

Palavras-chave: Monitoramento, Gestão Pedagógica, Prática Educativa, Aprendizagem.

\section{The Monitoring Educational Practice: Tools for Educational Management Efficient}

\begin{abstract}
This article aims to reflect on the practice of monitoring the development of teaching and learning, starting from field research and literature. The main objective of this study was to study the results obtained in classes of 2nd year of elementary school in the city of Iguatu, in order to identify which contributions of the pedagogical action of the schools studied. The results led us to believe that these were directly favorable in the success of school results.
\end{abstract}

Keywords: Monitoring, Pedagogical Management, Educational Practice, Learning.

\section{Introdução}

Os desafios da escola pública na atualidade e simultaneamente a complexidade dos processos educativos que nela ocorrem evidenciam a necessidade de ações diretivas que fomentem intervenções pedagógicas e educacionais que produzam resultados de uma aprendizagem de qualidade.

O trabalho escolar é cada vez mais complexo e, portanto carece de mecanismos que possibilitem o desenvolvimento qualitativo dos processos de ensino e aprendizagem com foco na ação fim da escola, ou seja, na aprendizagem dos alunos, e para tanto subsidie a equipe escolar de informações objetivas e em quantidade adequada para a tomada de decisão.

\footnotetext{
${ }^{1}$ Graduação em Pedagogia pela Universidade Estadual do Ceará, UECE, Brasil. Mestrado profissional em Mestrado em Ciências da Educação pela Universidades San Carlos, USC, Paraguai. Especialização em Gestão da Educação Pública. Universidade Federal de Juiz de Fora, UFJF; Especialização em Gestão Escolar. Universidade do Estado de Santa Catarina, UDESC; Especialização em Metodologia do Ensino Fundamental e Médio. Universidade Estadual do Ceará, UECE, Brasil.
} 
A prática do monitoramento, na administração pública, vem sendo fomentada através de diferentes iniciativas e em diferentes níveis de governo principalmente na área de controle social, de responsabilização do gasto público, como elemento potencializador de aprendizagem e de diálogo para a discussão das ações públicas institucionais e organizacionais.

$\mathrm{Na}$ educação, o monitoramento se concretiza na prática da verificação da concretude entre o planejamento, a ação e em quais e quanto dos objetivos foram alcançados, assim como na verificação dos aspectos ou problemas estão interferindo nos resultados esperados.

Nessa perspectiva este artigo busca, a partir da pesquisa conceitual e bibliográfica sobre a prática do monitoramento na educação, o conhecimento teórico e a práxis da ação de monitoramento, com vistas a contribuir de forma direta ou indireta na sinalização dos avanços e/ou retrocessos do processo educativo em aspectos pertinentes sobre a ação educativa escolar.

A pesquisa teve como objeto principal o estudo dos resultados obtidos nas turmas de $2^{\circ}$ ano do Ensino Fundamental na perspectiva de identificar quais contribuições da ação pedagógica das escolas pesquisadas foram diretamente favoráveis no alcance de resultados de sucesso escolar e quais fatos têm possibilitado o desafio de tornar a gestão pedagógica o instrumento de qualificação do processo de ensino e de aprendizagem.

\section{Conceituando Monitoramento}

A palavra monitor vem do latim: Monitum e significa "aquele que dá concelho, que faz pensar, adverte, que lembra." Todavia, historicamente essa ação foi vinculada á práticas tradicionais e equivocadas de controle e fiscalização.

Almeida, (2010, p. 19) defende que é necessário considerar as formas de controle já existentes mesmo antes do advento do capitalismo, como um dos fatores que justifica a resistência entre os profissionais a processos de monitoramento, pois, ao longo dos anos foram atribuídos fortemente significados e usos inadequados como algo cerceador e limitador e, portanto, negativo.

Contribui também para fortalecer essa concepção a identificação de todas as atividades que realizam algum tipo de acompanhamento dentro da administração pública como sendo ação de monitoramento, como por exemplo: auditorias de órgãos como CGU e TCU que realizaram ações fiscalizatórias visando apurar malversação de recursos públicos; acompanhamentos físico-financeiro de setores como Secretarias de Planejamento, Secretarias de Administração e 
Finanças dos Municípios, Estados ou Ministérios responsáveis pelo planejamento e gerenciamento orçamentário que trabalham com a verificação da situação da execução daquilo que foi planejado e inserido na peça orçamentária que disciplina os gastos e investimentos de programas, ações e projetos implementados por determinado órgão.

Em outra linha de atuação estão às pesquisas avaliativas realizadas para a compreensão dos motivos pelos quais determinadas ações públicas tomou tal ou qual configuração, se esse arranjo favorece a obtenção de resultados e se os resultados pretendidos foram alcançados. Trata-se, assim de importantes ferramentas para a melhoria dos programas e o alcance dos resultados.

Percebe-se, portanto, que tais campos se aproximam da noção de monitoramento como acompanhamento e controle de processos específicos de gestão, todavia o monitoramento está presente em diferentes campos de práticas e conhecimentos, apresentando um conjunto variado de possíveis interpretações. Na área administrativa, o monitoramento pode ser visto desde um instrumento de controle para a gestão de cadeias de suprimentos (ASTRTRÖM, 2012) e de automação de postos de gasolina (WEISSMAN et al, 2012) até como instrumento para gerenciar fatores de riscos em instituições públicas (RODRIGO, 2012).

Segundo Vaitsman, Rodrigues e Paes-Sousa, 2006, p. 21,

\begin{abstract}
Monitoramento consiste no acompanhamento contínuo, cotidiano, por parte de gestores e gerentes, do desenvolvimento dos programas e políticas em relação a seus objetivos e metas. É uma função inerente à gestão dos programas, devendo ser capaz de prover informações sobre o programa para seus gestores, permitindo a adoção de medidas corretivas para melhorar sua operacionalização. É realizado por meio de indicadores, produzidos regularmente com base em diferentes fontes de dados, que dão aos gestores informações sobre o desempenho de programas, permitindo medir se objetivos e metas estão sendo alcançados.
\end{abstract}

O monitoramento é uma das principais ferramentas utilizadas para potencializar o desempenho de um governo, organização, projeto. Dentre as principais funções está a retroalimentação do sistema de gestão, propiciando ações corretivas decorrentes dessa avaliação. Com esse proposito, o monitoramento precisa de indicadores coletados e calculados com uma periodicidade que permita aos gestores reagir ainda dentro do ciclo de execução do programa. Além disso, é preciso que as informações geradas pelos indicadores sejam apresentadas em formato de fácil consumo pelos gestores, ou seja, para que estes tenha uma rápida apreensão do desempenho do programa. 


\section{O Monitoramento da Prática Educativa}

A prática de monitoramento dos processos educacionais, embora comprovadamente essencial para o alcance de maior eficiência na alocação de recursos, de eficácia e qualidade dos serviços prestados assim como na produção de bases sustentáveis para auxiliar na tomada de decisões é ainda um dos principais desafios da gestão educativa.

Esse fato decorre, talvez, dentre outros motivos, porque sejam atribuídos significados e usos inadequados; o monitoramento é visto como um controle cerceador e limitador, portanto, negativo que por sua vez gera, entre os profissionais, fortes reações e até mesmo resistência.

Outro ponto pertinente a essa suposta resistência deve-se á vinculação do processo de monitoramento ao de avaliação, visto que os dois apontam resultados que necessariamente impõe ações de intervenções, sendo que se não for conduzido a partir do seu real significado pedagógico assumem caráter punitivo que se difunde acriticamente para outras práticas de monitoramento.

Segundo Luck, (2006 apud, LUCK, 2009, p. 44) “os índices de reprovação e distorção idade/série, presentes em nossas escolas são indicadores de uma prática inadequada de avaliação da aprendizagem escolar e de falta de monitoramento contínuo dos processos pedagógicos", situação que seguramente poderiam ser superada mediante uma prática de monitoramento que promova uma ação reflexiva e crítica pelos próprios profissionais que atuam na escola, com uma perspectiva de estudo sobre suas práticas e seus resultados.

Infelizmente esse entendimento do monitoramento de processos e de avaliação dos resultados das práticas educacionais como estratégia de gestão educacional foi desvalorizado pelas concepções denominadas críticas da educação. Segundo Luck, (2009),

\footnotetext{
Ao valorizarem as dimensões sociopolíticas, inadequadamente, desvalorizaram as dimensões técnicas, mediante a rotulação ligeira de "tecnicismo" dentre as quais a medida e a avaliação, que em muitas instituições formadoras de profissionais da educação desapareceram dos seus currículos, em prejuízo de uma formação voltada para as necessidades concretas do trabalho educacional. (LUCK, 2009, p. 44).
}

Como consequência tornou-se prática no cotidiano escolar a aplicação de instrumentos e processos aleatórios que apesar de identificar resultados, não havia mecanismos de interpretação dos mesmos que propiciasse uma reflexão para a retroalimentação das práticas educativas onde proporcionasse efetivamente subsídios para uma intervenção sobre os indicadores a partir da práxis pedagógica. 
O monitoramento é descrito por Lück (2009) como,

Um processo de acompanhamento sistemático e descritivo dos processos de implementação de plano ou projeto de ação, com o objetivo de garantir sua maior efetividade, mediante a verificação do seu ritmo de trabalho, o bom uso do tempo e dos recursos, a aplicação adequada das ações e competências previstas e necessárias, em relação aos resultados pretendidos. (LUCK, 2009, p.45).

Considerando essa descrição podemos afirmar que o monitoramento é um aspecto fundamental na efetivação da Gestão Pedagógica eficiente, tendo em vista que sua implementação determina em que medida o plano ou projeto estar alcançando os objetivos ou meta traçadas no planejamento da ação. Esse aspecto nos remete a uma constatação: a ação de monitoramento necessariamente deve estar precedida de um planejamento, pois esse por sua vez traduz um processo de diagnostico e de prospectiva a partir de uma realidade educacional identificada que se pretende intervir quando necessário.

Dessa forma podemos afirmar que o monitoramento é uma ação intencional onde segundo Aguiar, (2006, p. 5) é essencial para que o governante e o gestor conheçam a evolução da situação que enfrentam e apreciem os resultados de suas ações, de forma a ser possível à tomada de decisões que possam resultar em modificações tempestivas.

Para tanto algumas questões devem ser levadas em conta para que o monitoramento produza os resultados necessários ao objetivo para o qual ele foi destinado que no caso da Gestão Pedagógica é além de apresentar indicadores alcançados a partir das ações desenvolvidas, também fornecer informações para subsidiar a tomada de decisões em relação ao que foi planejado a partir do resultado alcançado.

Nessa perspectiva a informação é uma das principais questões e precisa ser bem direcionada no sentido de que sua produção tenha foco, ou seja, haja seleção a partir do que é fundamental para a produção de indicadores concretos e direcionados aos interesses específicos para as quais foram produzidas. Ainda com relação à informação é preciso atentar para necessidade da retroalimentação, em virtude da dinâmica escolar, e nesse aspecto a informação pode tornar-se mais eficiente se sua produção for descentralizada, pois dessa forma permite sua eficácia pelo ganho do tempo em que pode ser produzida. Assim o tempo é outro aspecto a ser levado em conta no monitoramento, pois a eficácia das informações estar intrinsecamente ligada à intervenção que será feita na ação que estar sendo desenvolvida, dessa forma é essencial que a informação chegue até o gestor em tempo de se produzir uma nova ação corretiva. 


\section{Resultados de uma Práxis de Monitoramento}

A experiência que apresentamos a seguir foi extraída de uma pesquisa que teve como objeto de estudo os diversos aspectos, procedimentos e instrumentos da gestão pedagógica da rede municipal de ensino de Iguatu. $\mathrm{O}$ objetivo da pesquisa foi identificar os fatores que qualificam a gestão pedagógica na melhoria dos indicadores aprendizagem.

$\mathrm{O}$ estudo apontou o papel do coordenador pedagógico, o monitoramento da prática educativa, os resultados das avaliações externas e, os recursos financeiros como atividades e/ou aspectos pertinentes à ação pedagógica seja no cotidiano da escola e/ou da sala de aula, que de forma geral estão diretamente relacionados e são responsáveis pela qualidade da Gestão Pedagógica. Todavia, destacamos nesse artigo, as principais evidências relevadas pela pesquisa no que se refere ao Monitoramento da Pratica Educativa:

A análise da ação do Monitoramento da Prática Educativa realizada pelos coordenadores pedagógicos no período pesquisado foi focada nas principais ações desenvolvidas no cotidiano escolar: visita á sala de aula, análise dos diários de classe, análise do planejamento do professor, análise dos consolidados dos resultados das turmas, planejamento didático, realização de momentos formativos. A observação norteou-se na identificação da frequência, como e de que forma as ações ocorriam.

Os dados apresentados, através da pesquisa realizada demonstra que o monitoramento da prática pedagógica desenvolvida no período pesquisado tinha características bem delineadas como:

- Ações contínuas e sistemáticas, embora se pôde perceber que em algumas escolas a ação fosse mais focada que outras;

- Homogeneidade nas ações, todavia as peculiaridades de cada escola favorecesse pertinência em umas ações em detrimento de outras, como também dificuldades de desenvolvimento das ações;

- Os coordenadores apresentaram clareza no entendimento e desenvolvimento das atividades;

- Ação focada no acompanhamento dos alunos individualmente, de cada turma em particular e da escola como um todo, assim como nas individualidades de cada professor, com intervenções planejadas a partir das necessidades e dificuldades encontradas;

- Registros da ação e feedback em tempo hábil o que favorecia a intervenção imediata; 
- O planejamento e a intervenção da ação sempre pautada nos resultados de aprendizagem obtidos por avaliações diagnósticas e avaliações externas.

Pode-se concluir que os monitoramentos das práticas educativas tiveram papel importantíssimo no alcance dos resultados alcançados no período pesquisado, tendo em vista que essa ação favoreceu o acompanhamento dos alunos individualmente, de cada turma em particular e da escola como um todo.

O desenvolvimento de ações de apoio, estudo e intervenção junto aos professores como parte rotineira do processo de tomada de decisão na escola foi outro fator preponderante, pois, favoreceu além do fornecimento de dados sistemáticos, enriquecendo os processos de planejamentos e colaborando com o redimensionamento dos aspectos de organização, funcionamento e métodos de ensino e avaliação.

$\mathrm{Na}$ análise das atividades desenvolvidas pelos coordenadores pedagógicos que foram descritas na pesquisa nos remete a uma percepção de movimento continuo e sistemático de ações planejamento, monitoramento, avaliação e intervenções, que trouxe como consequência uma mobilização interna concentrando alunos, professores e pais em torno da discussão do trabalho da escola e principalmente da aprendizagem promovendo assim a geração de altas expectativas em relação aos resultados escolares e consequentemente a melhoria dos mesmos.

\section{Conclusão}

O estudo bibliográfico referendado pela pesquisa de campo nos mostrou que monitoramento é um aspecto fundamental na efetivação da Gestão Pedagógica e que para de fato produza os resultados aos quais se propõe aspectos como o fornecimento de informações, o tempo destinado à ação e o acompanhamento do desenvolvimento dessas ações são essenciais para que a informação chegue até o gestor em tempo de se produzir uma nova ação corretiva.

Analisando sobre o monitoramento do coordenador pedagógico em relação à prática educativa dos professores, constata-se que ela traduz em termos mais práticos a ação direta do coordenador pedagógico, ou seja, a forma como a gestão pedagógica foi desenvolvida na escola integrando e/ou direcionando às demais dimensões educativas que interferem diretamente nos fatores pedagógicos. Dessa forma, quando analisamos as informações nos questionários, percebemos claramente que nesse período houve nas escolas além de uma atuação focada do 
coordenador pedagógico, junto à sala de aula e aos professores, a execução de ações planejadas e coordenadas a partir da priorização das necessidades de cada situação diagnosticada no chão da sala de aula. Tudo isto, favoreceu a elevação dos indicadores de aprendizagem e em alguns casos, referendando ações de planejamento sistemático e sustentável.

A implementação efetiva do monitoramento das práticas educativas, como ação sistemática nas escolas, contribuiu para que as ações fossem melhores direcionadas e priorizadas com foco na melhoria dos indicadores de aprendizagem dos alunos.

A partir do que foi apresentado podemos concluir que o monitoramento é, pois um dos instrumentos de trabalho do Coordenador Pedagógico na sua prática cotidiana, tendo em vista que a efetiva pratica desse mecanismo subsidiará todo o trabalho da gestão.

\section{Referências}

AGUIAR M. A. S. et al. Diretrizes curriculares do curso de pedagogia no Brasil: disputas de projetos no campo da formação do profissional da educação. Revista Educação e

Sociedade, Campinas, v. 27, n. 96, p. 819-842, out. 2006.

ALMEIDA, Claudia Mara de. SOARES, Katia Cristina D. Pedagogo Escolar - As funções supervisoras e orientadoras. IBPEX, 2010.

ARAÚJO, Maria Benildes Uchôa. Gestão Pedagógica: Estudo Exploratório da Gestão Pedagógica no Município de Iguatu-Ceará no período de 2008 a 2012. Assunção - PY, 2016

ASTRÖM M, ASPLUND K, ASTRÖM T. Psychosocial function and life satisfaction after stroke. Stroke. 1992;23(4):527-31.

KASEN, S., WICKRAMARATNE, P., GAMEROFF, M. J., \& WEISSMAN, M. M. (2012). Religiosity and resilience in persons at high risk for major depression. Psychological Medicine, 42(4), 509-519.

LÜCK, Heloísa. Toda a força para o líder. Nova Escola. Gestão Escolar. Editora Abril. Ano I. Nº1. Abri/maio. 2009.

\section{Como citar este artigo (Formato ABNT):}

SANTOS, Ioneide S.; ARAÚJO, Giovana F. Satisfação e Insatisfação dos Agentes Comunitários de Saúde no Trabalho no Município de Itapetinga-Bahia. Id on Line Revista Multidisciplinar e de Psicologia, 2017, vol.11, n.38, p.728-735. ISSN: 1981-1179.

Recebido: 07.11.2017

Aceito: 08.11.2017 